\title{
Visceral adipose tissue is not increased in Pima Indians compared with equally obese Caucasians and is not related to insulin action or secretion
}

\author{
J.-F. Gautier ${ }^{1}$, M. R. Milner ${ }^{1}$, E. Elam ${ }^{2}$, K. Chen ${ }^{2}$, E. Ravussin ${ }^{1}$, R. E. Pratley ${ }^{1}$ \\ ${ }^{1}$ Clinical Diabetes and Nutrition Section, Phoenix Epidemiology and Clinical Research Branch, National Institute of Diabetes \\ and Digestive and Kidney Diseases, National Institutes of Health, Phoenix, Arizona, UK \\ ${ }^{2}$ Department of Radiology, Good Samaritan Regional Medical Center, Phoenix, Arizona, UK
}

\begin{abstract}
Summary Pima Indians are insulin resistant and hyperinsulinaemic compared with Caucasians. We investigated whether abdominal fat distribution was different between Pimas and Caucasians and whether differences in the amount of visceral fat explained metabolic differences between the groups. Total body fat (absorptiometry) and abdominal fat distribution at L4-L5 (magnetic resonance imaging) were compared in 20 Pima Indians (10 men/10 women) and 20 age-, sex- and BMI-matched Caucasians. Insulin action was measured as glucose disposal during a two-step hyperinsulinaemic-euglycaemic glucose clamp and insulin secretion was assessed in response to oral and intravenous glucose tolerance tests. By design, percent body fat was similar in Pimas and Caucasians. Abdominal visceral and subcutaneous adipose tissue areas were also similar in the two groups $\left(151 \pm 16\right.$ vs $139 \pm 15 \mathrm{~cm}^{2}$ and $489 \pm 61$ vs $441 \pm 57 \mathrm{~cm}^{2}$ respectively). Plasma insulin concentra-
\end{abstract}

tions were higher in Pimas than Caucasians in the fasting state $(27 \pm 6$ vs $11 \pm 2 \mathrm{mU} / \mathrm{ml} ; p<0.01)$ and after a 75-g oral glucose load (area under the curve $19975 \pm 2626$ vs $9293 \pm 1847 \mathrm{mU} \cdot \mathrm{l}^{-1} \cdot 180 \mathrm{~min}^{-1}$; $p<0.005)$. Glucose disposal was lower in Pimas than Caucasians during both steps of the clamp and negatively correlated (after adjustment for percent body fat and sex) with visceral adipose tissue in Caucasians (partial $r=-0.51, p=0.03$ ), but not in Pima Indians $(r=-0.03, p=0.92)$. Insulin secretion was not related to visceral fat independently of percent body fat in either group. We conclude that a relative increase in visceral fat does not explain insulin resistance and hyperinsulinaemia in Pima Indians. [Diabetologia (1999) 42: 28-34]

Keywords Abdominal obesity, insulin resistance, insulin secretion, Pima Indians.
Received: 18 May 1998 and in revised form: 28 July 1998

Corresponding author: Dr. J.-F. Gautier, Clinical Diabetes and Nutrition Section, NIDDK/NIH, 4212 North 16th Street, Phoenix, Arizona, 85016, USA

Abbreviations: CT, computed tomography; MRI, magnetic resonance imaging; VAT, visceral adipose tissue; SAT, subcutaneous abdominal tissue; OGTT, oral glucose tolerance test; AIR, acute insulin response to a $25-\mathrm{g}$ bolus dextrose injection; $\mathrm{AUC}_{\text {glucose }}$, area under the curve of glucose concentrations above basal value during OGTT over 3 hours; $\mathrm{AUC}_{\text {insulin, }}$, area under the curve of insulin concentrations above basal value during OGTT over 3 hours; $\mathbf{M}$, glucose disposal rate at a mean plasma insulin concentration of $80 \mathrm{mU} / 1\left(\mathrm{M}_{80}\right)$ and $1760 \mathrm{mU} / \mathrm{l}\left(\mathrm{M}_{1760}\right)$ during euglycaemic glucose clamp; DEXA, dual-energy $\mathrm{x}$-ray absorptiometry.
Several prospective studies have shown that obesity is a risk factor for Type II (non-insulin-dependent) diabetes mellitus, dyslipidaemia, hypertension and atherosclerotic cardiovascular disease [1-3]. In 1956, it was suggested that the pattern of body fat distribution also was an important determinant of the complications of obesity [4]. This was later confirmed by studies indicating that an upper body fat distribution poses a greater risk for Type II diabetes and cardiovascular disease than obesity per se [5-8]. Simple anthropometric indices of the pattern of body fat distribution such as the waist-to-hip ratio [9] and waist-tothigh ratio [3], do not distinguish visceral adipose tissue (VAT; which could be metabolically more active) from subcutaneous abdominal adipose tissue (SAT). Computed tomography (CT) and magnetic reso- 
nance imaging (MRI) can be used to measure abdominal visceral and subcutaneous adipose tissue and these studies indicate that insulin resistance, increased blood pressure, and dyslipidaemia are more prevalent in subjects having a higher proportion of VAT [10-12]. Consistent with these data, subjects with Type II diabetes have more VAT than non-diabetic subjects independent of body weight [13-14] and VAT is related to insulin resistance in Caucasians with Type II diabetes [15]. Furthermore, a prospective study in Japanese-American men showed that increased VAT precedes the development of Type II diabetes [16].

The Pima Indians of Arizona have the highest reported prevalence of Type II diabetes in the world [17]. When compared with Caucasians, non-diabetic Pima Indians are less sensitive to the action of insulin, secrete more insulin and tend to have a more abdominal pattern of body fat distribution, as assessed by the waist-to-thigh circumference ratio [18]. Whether these differences are the consequence of a greater proportion of visceral fat is not known. The aim of the present study was to determine whether visceral fat was increased in non-diabetic Pima Indians relative to similarly obese Caucasians and to investigate the relation between insulin action and secretion and the distribution of adipose tissue in these groups. Insulin action was measured using the two-step hyperinsulinaemic-euglycaemic glucose clamp technique and insulin secretion was assessed from oral and intravenous glucose tolerance tests.

\section{Subjects and methods}

Subjects. We studied 20 Pima Indians (10 men and 10 women) and 20 Caucasian controls. Caucasians were recruited from local newspaper advertisements and matched for sex, age ( \pm 5 years) and BMI $\left( \pm 3 \mathrm{~kg} / \mathrm{m}^{2}\right)$ to Pima Indians. All subjects were in good health as determined by physical examination and routine blood and urine tests. None were diabetic [19] or took prescribed or over-the-counter medications. This study was approved by the ethics committee of the National Institute of Diabetes and Digestive and Kidney Diseases and by the Tribal Council of the Gila River Indian Community and all subjects gave written informed consent prior to participation. Subjects were admitted to the Clinical Research Unit for 7-10 days and were provided a standard weight-maintaining diet containing $50 \%$ carbohydrate, $30 \%$ fat and $20 \%$ protein for at least 3 days prior metabolic testing. While on the unit, all subjects were restricted to sedentary activities only.

Body composition and abdominal fat distribution. Fat mass, fat-free mass and percent fat were measured in total body, trunk and legs by dual-energy x-ray absorptiometry (DEXA) using a total body scanner (DPX-L, Lunar Radiation Corp, Madison, Wis., USA) as described previously [20]. Waist circumference was measured at the umbilicus while supine and thigh circumference at the gluteal fold while standing. Waist circumference and the waist:thigh circumference ratio were used as indices of the pattern of body fat distribution [18].
Magnetic resonance imaging was done using a General Electric 1.5 T Sigma scanner (General Electric, Milwaukee, Wis., USA) which acquired a series of cross-sectional T-1 weighted scans centered around L4-L5. Visceral and subcutaneous fat areas were measured on a single scan at the bifurcation of the aorta (approximately the 4th-5th lumbar interspace) after manually drawing regions of interest using image analysis software (Image, NIH, Bethesda, Md., USA). Subcutaneous abdominal tissue (SAT) area (in $\mathrm{cm}^{2}$ ) was quantified as the difference between total abdominal area and a region of interest drawn at the demarcation of the subcutaneous and intra-abdominal tissue. A histogram of pixel intensity in the intra-abdominal region was displayed and the intensity corresponding to the nadir between the lean and fat peaks was used as a cutpoint. Visceral adipose tissue (VAT) was taken as the summed area of the pixels in the intraabdominal region above this cutpoint. Total abdominal fat area was calculated as the sum of the SAT and VAT.

Metabolic measurements. An oral glucose tolerance test (OGTT) with $75 \mathrm{~g}$ of glucose was done after 3 days on the research ward. Venous blood samples were collected for the determination of plasma glucose and insulin concentrations at $-15,0,30,60,120$, and $180 \mathrm{~min}$. Fasting glucose and insulin concentrations were taken as the mean of the samples obtained at -15 and 0 min. Glucose and insulin responses were calculated as areas under the curve above fasting values over $3 \mathrm{~h}$. The acute insulin response (AIR) to a 25 -g bolus dextrose injection was calculated as the mean of the change in plasma insulin concentrations above basal value from the 3 rd to the 5 th min after the glucose injection. Since even mild degrees of glucose intolerance can secondarily affect insulin secretion, AIR was only examined in a subgroup of 13 Pima Indians and 12 Caucasians with normal glucose tolerance (2-h glucose $<7.8 \mathrm{mmol} / \mathrm{l}$ ). Approximately 7 days after admission, a 2-step hyperinsulinaemic-euglycaemic glucose clamp was done, as described previously [3]. Briefly, a primed infusion of regular insulin (Novo-Nordisk, Bethesda, Md., USA) was given at a dose of $40 \mathrm{mU} / \mathrm{m}^{2}$ body surface area a min for $100 \mathrm{~min}$ and at a dose of $400 \mathrm{mU} \cdot \mathrm{m}^{-2} \cdot \mathrm{min}^{-1}$ for an additional $100 \mathrm{~min}$. These infusions produced mean steady-state plasma insulin concentrations of $80 \pm 5 \mathrm{mU} / \mathrm{l}$ during the low dose and $1760 \pm 170 \mathrm{mU} / \mathrm{l}$ during the high dose. Endogenous glucose production was measured during the low dose using a primed-continuous infusion of $\left[3-{ }^{3} \mathrm{H}\right]$-glucose. As described previously, glucose disposal $(\mathrm{M})$ during the clamp was adjusted for differences in steady-state plasma glucose concentrations, expressed per kilogram of estimated metabolic body size (MBS = fat free mass + 17.7) and corrected for endogenous glucose production (assumed to be 0 during the high dose) [21].

Statistical analysis. All data were analysed using the procedures of the SAS Institute (SAS, Inc., Cary, N. C., USA). Plasma insulin concentrations and $\mathrm{M}_{80}$ were not normally distributed and were therefore $\log _{10}$ transformed prior to parametric analyses. Ethnic and sex differences were tested using analysis of variance or the non-parametric Wilcoxon rank test. Pearson correlation coefficients were calculated to determine the relation between selected variables. Multiple regression models assessed the independent effects of total body fat and abdominal fat distribution on carbohydrate metabolism. Within each race, partial correlation coefficients were calculated to determine the relation between indices of carbohydrate metabolism and abdominal fat areas independently of percent body fat and sex. In addition, stepwise regression analyses were performed entering glucose disposal rate as the dependent variable and 
VAT, SAT, percent body fat, race and sex as independent variables. Data are expressed as means \pm SEM and $p$ values less than 0.05 are considered significant.

\section{Results}

The physical characteristics of the Pima Indians and Caucasians are compared in Table 1. By design, the groups were similar in age and BMI. Percent body fat was slightly, although not significantly, higher in Pimas than in Caucasians. The waist circumference was slightly higher, whereas the thigh circumference was slightly lower in Pimas. Although neither of these differences in circumference was statistically significant, the ratio of the waist circumference to the thigh circumference was higher in Pimas than Caucasians. Likewise, total fat mass was similar in the two groups, but fat mass in the trunk tended to be higher and fat mass in the legs was slightly less in the Pimas. The ratio of trunk to leg fat mass was consequently higher in Pimas than Caucasians. Despite their higher waist-tothigh circumference ratio and the apparent increase in fat mass in trunk relative to leg depots as measured by DEXA, neither VAT nor SAT were statistically significantly higher in Pimas than in Caucasians. The ratio of VAT to total abdominal fat area was also similar in the two groups.

The metabolic characteristics of the groups are summarized in Table 2. Fasting and 2-h plasma insulin concentrations were higher in Pima Indians than in controls. The plasma glucose area under the curve $\left(\mathrm{AUC}_{\text {glucose }}\right)$ during the OGTT was similar in the two groups $\left(454 \pm 50\right.$ and $395 \pm 44 \mathrm{mmol} / \mathrm{l} \cdot 180 \mathrm{~min}^{-1}$ in Pimas and Caucasians, respectively) whereas the plasma insulin area under the curve $\left(\mathrm{AUC}_{\text {insulin }}\right)$ was higher in Pima Indians than Caucasians $(p=0.0008)$. Among subjects with normal glucose tolerance, the acute insulin response to intravenous glucose (AIR) tended to be higher in Pima Indians $(n=13)$ than in Caucasians $(n=12)$ but this difference did not reach statistical significance $(p=0.17)$. Glucose disposal was 20-30\% lower in Pima Indians during both steps of the glucose clamp. Basal endogenous glucose production was similar in both groups averaging $11.87 \pm 0.34$ and $11.65 \pm 0.28 \mathrm{mmol} \cdot(\mathrm{kg}$. MBS) $)^{-1} \cdot \min ^{-1}$ in Caucasians and Pimas, respectively.

Correlation between body composition, fat distribution and glucose metabolism. Fasting insulin concentration correlated to waist circumference and SAT in Caucasians, but not in Pimas (Table 3). The 2-h plasma insulin concentration correlated with SAT in Pimas, but not in Caucasians. These relations did not, however, remain statistically significant after adjustment for percent body fat and sex. The $\mathrm{AUC}_{\text {insulin }}$ was not related to abdominal fat areas in either
Table 1. Subjects' physical characteristics and body composition

\begin{tabular}{lllll}
\hline & $\begin{array}{l}\text { Caucasians } \\
(n=20)\end{array}$ & $\begin{array}{l}\text { Pima Indians } \\
(n=20)\end{array}$ & $\begin{array}{l}\text { Difference } \\
(\%)\end{array}$ & $\begin{array}{l}\text { Race effect } \\
p \text { value }\end{array}$ \\
\hline Age $($ year $)$ & $32 \pm 3$ & $32 \pm 5$ & & 0.94 \\
Weight $(\mathrm{kg})$ & $96.1 \pm 5.7$ & $96.0 \pm 5.7$ & & 0.86 \\
Height $(\mathrm{cm})$ & $170 \pm 2$ & $165 \pm 2$ & -2.9 & 0.01 \\
BMI $\left(\mathrm{kg} / \mathrm{m}^{2}\right)$ & $33.4 \pm 2.9$ & $35.5 \pm 2.0$ & +6.3 & 0.39 \\
Waist $(\mathrm{cm})$ & $107 \pm 5$ & $112 \pm 5$ & +4.7 & 0.41 \\
Thigh $(\mathrm{cm})$ & $69 \pm 2$ & $67 \pm 2$ & -2.9 & 0.47 \\
Waist/thigh & $1.53 \pm 0.03$ & $1.67 \pm 0.04$ & +9.2 & 0.01 \\
$\%$ Body fat & $31.5 \pm 2.3$ & $34.5 \pm 2.4$ & +9.5 & 0.14 \\
FM & & & & \\
Total $(\mathrm{kg})$ & $37.3 \pm 4.2$ & $39.6 \pm 4.1$ & +6.1 & 0.67 \\
Trunk $(\mathrm{kg})$ & $18.4 \pm 2.2$ & $21.6 \pm 2.1$ & +17.4 & 0.27 \\
Legs $(\mathrm{kg})$ & $14.1 \pm 1.7$ & $13.0 \pm 1.7$ & -7.8 & 0.58 \\
Trunk/legs & $1.37 \pm 0.11$ & $1.80 \pm 0.12$ & +31 & 0.02 \\
FFM & & & & \\
Total $(\mathrm{kg})$ & $54.3 \pm 2.6$ & $49.7 \pm 2.5$ & -8.5 & 0.15 \\
Trunk $(\mathrm{kg})$ & $26.3 \pm 1.1$ & $24.9 \pm 1.3$ & -5.3 & 0.35 \\
Legs $(\mathrm{kg})$ & $18.4 \pm 1.1$ & $16.4 \pm 0.9$ & -10.9 & 0.12 \\
Trunk/legs & $1.47 \pm 0.04$ & $1.53 \pm 0.03$ & +4.1 & 0.27 \\
SAT $\left(\mathrm{cm}^{2}\right)$ & $441 \pm 57$ & $489 \pm 61$ & +10.9 & 0.52 \\
VAT $\left(\mathrm{cm}^{2}\right)$ & $139 \pm 15$ & $151 \pm 16$ & +8.6 & 0.60 \\
TAT $\left(\mathrm{cm}^{2}\right)$ & $580 \pm 63$ & $640 \pm 69$ & 9.4 & 0.49 \\
VAT/TAT & $0.28 \pm 0.03$ & $0.26 \pm 0.02$ & -7.1 & 0.54 \\
\hline
\end{tabular}

Means \pm SEM. WTR, waist-to-thigh ratio. FM, fat mass. FFM, fat free mass. SAT, subcutaneous abdominal adipose tissue area. VAT, visceral adipose tissue area. TAT, sum of visceral and abdominal subcutaneous adipose tissue areas. $P$ values were calculated by analysis of variance

group. Among subjects with normal glucose tolerance, AIR was not related to abdominal fat areas, even after adjustment for $\mathrm{M}_{80}$.

In Caucasians, $\mathbf{M}_{80}$ and $\mathbf{M}_{1760}$ were negatively correlated with VAT (Fig. 1). In contrast, in Pima Indians, the negative relation between $\mathrm{M}_{80}$ and VAT (Fig. 1) was weaker and non-significant and no correlation was seen between $\mathrm{M}_{1760}$ and VAT. In both Pima Indians and Caucasians $\mathrm{M}_{80}$ was negatively correlated with SAT. Endogenous glucose production was not related to VAT or SAT in either group.

In stepwise regression analyses, only race, VAT and SAT were related to $\mathrm{M}_{80}$ accounting for 31,17 and $7 \%$ of the variance in glucose disposal, respectively. These results were not changed after removing percent body fat from the analyses. After adjusting for percent body fat and waist-to-thigh ratio, race was still a determinant of fasting insulin, $\mathrm{AUC}_{\text {insulin, }}$ $\mathrm{M}_{80}$ and $\mathrm{M}_{1760}$. Because abdominal fat areas were related to percent body fat and sex, the relation between insulin action and abdominal fat areas were analysed after adjusting for percent body fat and sex. Among all anthropometric and MRI variables, VAT remained related to $\mathrm{M}_{80} \quad(p=0.029)$ and $\mathrm{M}_{1760}$ $(p=0.015)$ in Caucasians, but not in Pimas. The lower panels of Figure 1 depict the correlation between VAT and $\mathrm{M}_{80}$ after adjustment for percent body fat. 
Table 2. Glucose and insulin concentrations and insulin action/secretion

\begin{tabular}{|c|c|c|c|c|}
\hline & $\begin{array}{l}\text { Caucasians } \\
(n=20)\end{array}$ & $\begin{array}{l}\text { Pima Indians } \\
(n=20)\end{array}$ & $\begin{array}{l}\text { Difference } \\
(\%)\end{array}$ & $\begin{array}{l}\text { Race effect } \\
p \text { value }\end{array}$ \\
\hline $\begin{array}{l}\text { Glucose }(\mathrm{mmol} / \mathrm{l}) \\
\text { fasting } \\
\text { 2-h }\end{array}$ & $\begin{array}{l}4.6 \pm 0.1 \\
6.5 \pm 0.4\end{array}$ & $\begin{array}{l}4.9 \pm 0.2 \\
7.5 \pm 0.4\end{array}$ & $\begin{array}{r}+7.2 \\
+10.6\end{array}$ & $\begin{array}{l}0.03 \\
0.21\end{array}$ \\
\hline $\begin{array}{l}\text { Insulin }(\mathrm{mU} / \mathrm{l}) \\
\text { fasting } \\
2-\mathrm{h}\end{array}$ & $\begin{array}{l}10.5 \pm 1.7 \\
66.1 \pm 12.6\end{array}$ & $\begin{array}{c}27.4 \pm 6.2 \\
158.9 \pm 25.2\end{array}$ & $\begin{array}{l}+161 \\
+140\end{array}$ & $\begin{array}{l}0.007 \\
0.002\end{array}$ \\
\hline $\begin{array}{l}\mathrm{M}\left(\mathrm{mmol} \cdot \mathrm{kg} \mathrm{MBS}{ }^{-1} \cdot \mathrm{n}\right. \\
\mathrm{M}_{80} \\
\mathrm{M}_{1760}\end{array}$ & $\begin{array}{l}22.6 \pm 1.3 \\
54.3 \pm 3.1\end{array}$ & $\begin{array}{l}15.8 \pm 1.7 \\
42.2 \pm 3.0\end{array}$ & $\begin{array}{l}-29.7 \\
-22.2\end{array}$ & $\begin{array}{l}0.003 \\
0.009\end{array}$ \\
\hline $\begin{array}{l}\text { AUC }_{\text {insulin }} \\
\quad\left(\mathrm{mU} \cdot \mathrm{l}^{-1} \cdot 180 \mathrm{~min}^{-1}\right)\end{array}$ & $9293 \pm 1847$ & $19975 \pm 2626$ & +115 & 0.0008 \\
\hline AIR (mU/l) & $81 \pm 23$ & $147 \pm 43$ & +81 & $0.17^{\mathrm{a}}$ \\
\hline
\end{tabular}

Means \pm SEM, glucose disposal rate at a mean plasma insulin concentration of $80 \mathrm{mU} / \mathrm{l}\left(\mathrm{M}_{80}\right)$ and $1760 \mathrm{mU} / \mathrm{l}\left(\mathrm{M}_{1760}\right)$ during euglycaemia expressed as mmol per kilogram of estimated metabolic body size $(\mathrm{MBS}=$ fat free mass +17.7$)$ per min. $\mathrm{AUC}_{\text {in }}$ sulin, area under the curve of insulin concentrations above basal value during OGTT over $3 \mathrm{~h}$. AIR, acute insulin response ex- pressed as the mean of the change in plasma insulin concentrations relative to basal value from the third to the fifth minute after the intravenous glucose injection in subjects with normal glucose tolerance (13 Pima Indians and 12 Caucasians). $P$ value from ANOVA procedures. ${ }^{a} P$ value from Wilcoxon rank test

Table 3. Pearson's correlation coefficients between anthropometric measures and metabolic variables in Pima Indian and Caucasian subjects

\begin{tabular}{|c|c|c|c|c|c|c|c|c|c|c|}
\hline & \multicolumn{2}{|c|}{$\%$ body fat } & \multicolumn{2}{|c|}{ Waist $(\mathrm{cm})$} & \multicolumn{2}{|c|}{ Waist/thigh } & \multicolumn{2}{|c|}{ VAT $(\mathrm{cm})$} & \multicolumn{2}{|c|}{$\mathrm{SAT}(\mathrm{cm})$} \\
\hline & Pimas & Caucasians & Pimas & Caucasians & Pimas & Caucasians & Pimas & Caucasians & Pimas & Caucasians \\
\hline $\begin{array}{l}\text { Fasting } \\
\text { glucose }(\mathrm{mmol} / \mathrm{l}) \\
\text { insulin }(\mathrm{mU} / \mathrm{l})\end{array}$ & $\begin{array}{l}0.65^{\mathrm{a}} \\
0.45^{\mathrm{a}}\end{array}$ & $\begin{array}{l}0.44 \\
0.37\end{array}$ & $\begin{array}{l}0.61^{\mathrm{a}} \\
0.33\end{array}$ & $\begin{array}{l}0.30 \\
0.57^{\mathrm{a}}\end{array}$ & $\begin{array}{l}0.14 \\
0.15\end{array}$ & $\begin{array}{l}0.06 \\
0.38\end{array}$ & $\begin{array}{l}0.26 \\
0.16\end{array}$ & $\begin{array}{l}0.16 \\
0.42\end{array}$ & $\begin{array}{l}0.65^{\mathrm{a}} \\
0.30\end{array}$ & $\begin{array}{l}0.43 \\
0.45^{\mathrm{a}}\end{array}$ \\
\hline $\begin{array}{l}\text { AUC }_{\text {glucose }} \\
\left(\mathrm{mmol}^{-1} \cdot 180 \mathrm{~min}^{-1}\right)\end{array}$ & 0.10 & 0.41 & -0.04 & $0.54^{\mathrm{a}}$ & 0.21 & 0.16 & 0.20 & 0.32 & 0.03 & 0.41 \\
\hline $\begin{array}{l}\text { AUC }_{\text {insulin }} \\
\left(\mathrm{mU} \cdot 1^{-1} \cdot 180 \mathrm{~min}^{-1}\right)\end{array}$ & $0.62^{\mathrm{a}}$ & 0.49 & 0.57 & 0.57 & 0.44 & $0.63^{\mathrm{a}}$ & 0.53 & -0.1 & 0.46 & 0.51 \\
\hline $\begin{array}{l}\mathrm{M}_{80} \\
\left(\mathrm{mmol} \cdot \mathrm{kg} \mathrm{MBS}^{-1} \cdot \mathrm{min}^{-1}\right)\end{array}$ & -0.44 & $-0.48^{a}$ & $-0.51^{\mathrm{a}}$ & $-0.64^{\mathrm{a}}$ & $-0.47^{\mathrm{a}}$ & $-0.56^{\mathrm{a}}$ & -0.39 & $-0.64^{\mathrm{a}}$ & $-0.50^{\mathrm{a}}$ & $-0.46^{\mathrm{a}}$ \\
\hline $\begin{array}{l}\mathbf{M}_{1760} \\
\left(\mathrm{mmol} \cdot \mathrm{kg} \mathrm{MBS}^{-1} \cdot \mathrm{min}^{-1}\right)\end{array}$ & -0.36 & -0.13 & -0.23 & -0.39 & -0.11 & -0.39 & -0.09 & $-0.65^{\mathrm{a}}$ & -0.31 & -0.18 \\
\hline AIR (mU/l) & 0.27 & 0.32 & 0.12 & 0.48 & 0.26 & $0.68^{\mathrm{a}}$ & -0.18 & 0.22 & 0.09 & 0.35 \\
\hline
\end{tabular}

$\mathrm{AUC}_{\mathrm{glucose}}$ and $\mathrm{AUC}_{\text {insulin }}$, areas under the curve of glucose and insulin concentrations above basal value during OGGT over $3 \mathrm{~h}$. M, glucose disposal rate at a mean plasma insulin concentrations of $80 \mathrm{mU} / \mathrm{l}\left(\mathrm{M}_{80}\right)$ and $1760 \mathrm{mU} / \mathrm{l}\left(\mathrm{M}_{1760}\right)$ expressed as mmol per kilogram of estimated metabolic body size $(\mathrm{MBS}=$ fat free mass +17.7$)$ per min. AIR, acute insulin re-

\section{Discussion}

Abdominal obesity is associated with a number of adverse metabolic conditions including insulin resistance, hyperinsulinaemia and glucose intolerance. Visceral fat depots are higher in overweight Caucasian and lean Japanese-American patients with Type II diabetes relative to non-diabetic controls of similar BMI [13-14]. Since the Pima Indians of Arizona have the highest reported prevalence of Type II diabetes [17] and tend to have an abdominal pattern of fat distribution [18], we hypothesized that visceral fat was sponse expressed as the mean of the change in plasma insulin levels relative to basal value from the third to the fifth minute after the intravenous glucose injection. Analysis with $\mathrm{AUC}_{\text {insu- }}$ lin and AIR were restricted to subjects with normal glucose tolerance (13 Pima Indians and 12 Caucasians). ${ }^{\mathrm{a}} p<0.05$

increased and was related to insulin resistance and hyperinsulinaemia in this population. Despite having a higher waist-to-thigh ratio, neither visceral nor subcutaneous abdominal fat areas were higher in Pimas than in Caucasians with similar degrees of obesity. Moreover, insulin action and secretion were not related to the amount of visceral adipose tissue in Pima Indians. These results suggest distinct mechanisms of insulin resistance in Pima Indians compared with Caucasians.

In contrast to the weak correlation between VAT and insulin action observed in Pima Indians, there 


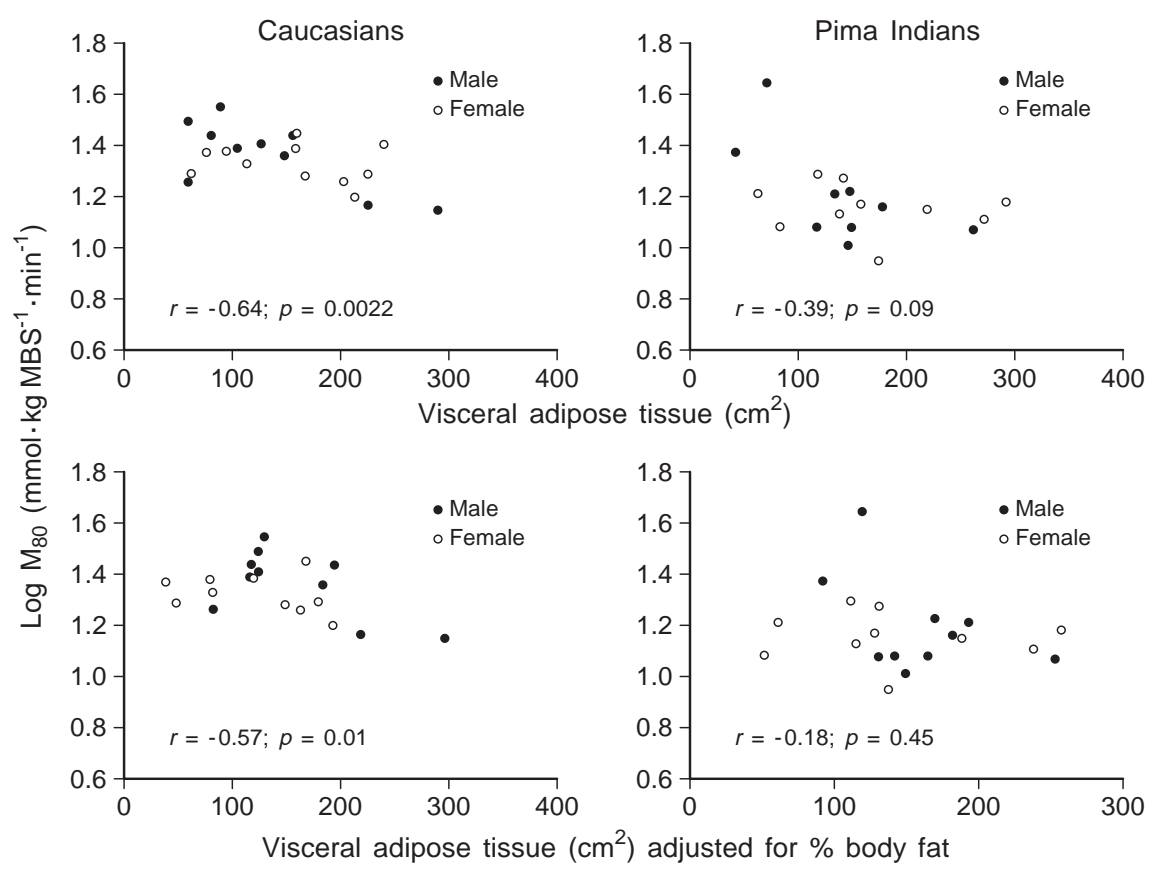

Fig. 1. Relation between glucose disposal rate (M) during low dose insulin infusion and visceral adipose tissue area in Pima Indians (right panels) and Caucasians (left panels). Lower figures depict the relation between glucose disposal rate and visceral adipose tissue after adjustment for percent total body fat. Pearson's coefficients were calculated after log transformation of glucose disposal rate

was a negative correlation between the amount of visceral fat and insulin action in Caucasians, confirming the findings of many previous reports. The disparate results in Pimas and Caucasians suggests that ethnicity can affect the relation of insulin action and VAT. Few studies have directly investigated this possibility. In African-American with Type II diabetes insulin-mediated glucose uptake was strongly correlated with visceral adipose tissue [22]. In Korean subjects, visceral adipose tissue areas were related to glucose disposal rate [23]. In Japanese subjects the ratio of visceral to subcutaneous fat area was related to plasma glucose area during OGTT [11]. Increased amounts of visceral fat predicted the onset of Type II diabetes in Japanese-American men [16]. Thus, the relation between the amount of visceral fat and impairments in glucose metabolism does not appear to be restricted to Caucasians. Our observation that Pima Indians are insulin resistant, yet have similar amounts of visceral fat, relative to equally obese Caucasian control subjects, suggests that an additional mechanism contributes to insulin resistance in the Pimas. Such a mechanism could weaken any correlation between insulin action and VAT in the Pimas.

In addition to being more insulin resistant, Pima Indians typically have higher insulin secretory responses than Caucasians [18]. Since it has been sug- gested that increased VAT impairs hepatic insulin clearance resulting in peripheral hyperinsulinaemia, we sought to establish whether differences in insulin responses to oral and intravenous tolerance tests between Pima Indians and Caucasians were related to VAT. Consistent with previous comparisons, insulin responses were higher in Pima Indians than in matched Caucasian control subjects [18]. Neither AIR nor $\mathrm{AUC}_{\text {insulin }}$ were related, however, to abdominal fat areas in Pimas or in Caucasians, even after adjusting for the differences in $\mathrm{M}_{80}$ between the groups. Similarly, no correlation was found between visceral adipose tissue and first phase insulin secretion as evaluated by the minimal model method and only a weak correlation between second phase insulin secretion and visceral fat [24]. Thus, the results of the present study do not support a role for visceral fat in the aetiology of the higher insulin responses to oral and intravenous glucose stimuli in Pimas compared with Caucasians.

Differences in food intake and physical activity could account for the ethnic differences in metabolic function observed in the present study. Diet and exercise were controlled, however, over the short term by admitting subjects to the Clinical Research Center at least 3 days prior to the study. Moreover, we have shown previously that energy and macronutrient intakes (fat, carbohydrate and protein) are similar in Pima Indians compared with participants in the third National Health and Nutrition Examination Survey [25]. Thus, the differences in metabolic function between similarly obese Pimas and Caucasians and the large differences in risk for diabetes between these two groups suggest that unique genetic factors contribute to insulin resistance and hyperinsulinaemia in Pima Indians [26]. 
Although an increase in VAT is most commonly implicated in the metabolic complications of abdominal obesity, the accumulation of fat in subcutaneous abdominal depots could be metabolically disadvantageous as well. Several studies have shown that the negative correlation between insulin-mediated glucose uptake and SAT is greater than that observed between insulin action and VAT [27-29]. For example, when the entire abdominal region using contiguous axial $10-\mathrm{mm}$ slices were scanned to determine visceral and subcutaneous adipose tissue volumes it was found that SAT correlated more strongly to glucose disposal than did VAT [27, 28]. It has also been shown that SAT at the L4-L5 level is more strongly correlated with glucose disposal than VAT [29], but this study included women who were thinner and had less VAT than those in our study. In our study, VAT was more strongly correlated to insulin action than was SAT in Caucasians but not in Pima Indians where the reverse was true. In the group as a whole, stepwise regression analyses indicated that both VAT and SAT are associated with insulin action.

The waist-to-thigh ratio, an index of the pattern of body fat distribution, was higher in Pima Indians than in Caucasians in our study. Surprisingly, this tendency toward a more abdominal distribution of fat was not reflected by an increase in VAT or SAT among the Pimas. By design, the groups were well matched for weight and BMI. Total body fat mass was also quite similar in the two groups but fat free mass tended to be lower in Pima Indians than in Caucasians. The waist circumference was slightly, although not significantly, higher in Pimas than Caucasians and the thigh circumference was slightly less. Consequently, the waist-to-thigh ratio was higher. Similar differences between the groups were noted in the regional measures of body composition. Truncal fat mass, measured by DEXA, was slightly, although not significantly, higher in the Pimas whereas fat mass in the legs was, if anything, less in the Pimas. The ratio between trunk and leg fat mass was, thus, higher in Pimas than Caucasians, mirroring the higher waist-tothigh ratio. The tendency for Pima Indians to have a more abdominal distribution of body fat compared with similarly obese Caucasians could, in part, be because for a given degree of obesity, Pimas have smaller legs (with both fat mass and fat-free mass less than in Caucasians). Both VAT and SAT reflect the amount of truncal fat, hence were similar in Pimas and Caucasians. Thus, the differences in the relative distribution of fat between the groups (indexed as the waist-to-thigh ratio) do not result from the preferential accumulation of fat in visceral depots and do not explain the differences in metabolic function between Pimas and Caucasians.

Although the results of this study suggest that differences in insulin action and insulin secretion between Pima Indians and Caucasians are not ex- plained by differences in the amount of visceral fat, these findings must be interpreted with caution due to the small sample size in each of the groups studied. It is particularly important to be circumspect in drawing conclusions from the multiple regression analyses in which there was only borderline power. Moreover, certain measurements such as VAT, SAT and percent body fat are highly intercorrelated. Thus, multicollinearity is a potential problem in multiple regression analyses which could make discerning the separate and independent effects of these variables difficult.

In conclusion, Pima Indians have similar amounts of visceral and subcutaneous adipose tissue compared to age-, sex-, and BMI-matched Caucasians, but are less sensitive to the metabolic action of insulin and secrete more insulin. Furthermore, VAT is not highly correlated with insulin resistance in Pima Indians. Thus, the higher prevalence of insulin resistance, hyperinsulinaemia and Type II diabetes in Pima Indians compared with Caucasians cannot be attributed to the preferential accumulation of fat in visceral depots in Pimas.

Acknowledgements. The authors thank the research volunteers without whose patience and willing participation this study would not have been possible. The excellent work and dedication of the technical and nursing staffs of the Clinical Research Unit are gratefully acknowledged.

\section{References}

1. Hubert HB, Feinleib M, McNamara PM, Castelli WP (1983) Obesity as an independent risk factor for cardiovascular disease: a 26-year follow-up of participants in the Framingham Heart Study. Circulation 67: 968-977

2. Manson JE, Colditz GA, Stampfer MJ et al. (1990) A prospective study of obesity and risk of coronary heart disease in women. N Engl J Med 322: 882-889

3. Lillioja S, Mott DM, Spraul M et al. (1993) Insulin resistance and insulin secretory dysfunction as precursors of non-insulin-dependent diabetes mellitus. N Engl J Med 329: 1988-1992

4. Vague J (1956) The degree of masculine differentiation of obesities: a factor determining predisposition to diabetes, atherosclerosis, gout, and uriccalcuous disease. Am J Clin Nutr 4: 20-34

5. Evans DJ, Hoffmann RG, Kalkhoff RK, Kissebah AH (1984) Relationship of body fat topography to insulin sensitivity and metabolic profiles in premenopausal women. Metabolism 33: 68-75

6. Ohlson LO, Larsson B, Svärdsudd K et al. (1984) The influence of body fat distribution on the incidence of diabetes mellitus: 13.5 years of follow-up of the participants in the study of men born in 1913. Diabetes 34: 1055-1058

7. Larsson B, Seidell J, Svardsudd K et al. (1989) Obesity, adipose tissue distribution and health in men - the study of men born in 1913. Appetite 13: 37-44

8. Haffner SM, Stern MP, Hazuda HP, Pugh J, Patterson JK (1987) Do upper-body and centralized adiposity measure different aspects of regional body-fat distribution? Relationship to non-insulin-dependent diabetes mellitus, lipids, and lipoproteins. Diabetes 36: 43-51 
9. Kissebah AH, Vydeligum N, Murray R et al. (1982) Relation of body fat distribution to metabolic complications of obesity. J Clin Endocrinol Metab 54: 254-260

10. Sparrow D, Borkan GA, Gerzof SG, Wisniewski C, Silbert CK (1986) Relationship of fat distribution to glucose tolerance. Results of computed tomography in male participants of the normative aging study. Diabetes 35: 411-415

11. Fujioka S, Matsuzawa Y, Tokunaga K, Tarui S (1987) Contribution of intra-abdominal fat accumulation to the impairment of glucose and lipid metabolism in human obesity. Metabolism 36: 54-59

12. Després JP, Nadeau A, Tremblay A et al. (1989) Role of deep abdominal fat in the association between regional adipose tissue distribution and glucose tolerance in obese women. Diabetes 38: 304-309

13. Shuman WP, Newell-Morris LL, Leonetti DL et al. (1986) Abnormal body fat distribution by CT in diabetic men. Invest Radiol 21: 483-487

14. Gray DS, Fujioka K, Colletti PM et al. (1991) Magneticresonance imaging used for determining fat distribution in obesity and diabetes. Am J Clin Nutr 54: 623-627

15. Gautier JF, Mourier A, de Kerviler E (1998) Evaluation of abdominal fat distribution in non-insulin-dependent diabetes mellitus: relationship to insulin resistance. J Clin Endocrinol Metab 83: 1306-1311

16. Bergstrom RW, Newell-Morris LL, Leonetti DL, Shuman WP, Wahl PW, Fujimoto WY (1990) Association of elevated fasting C-peptide level and increased intra-abdominal fat distribution with development of NIDDM in JapaneseAmerican men. Diabetes 39: 104-111

17. Knowler WC, Bennett PH, Hamman RF, Miller M (1978) Diabetes incidence and prevalence in Pima Indians: a 19fold greater incidence than in Rochester, Minnesota. Am J Epidemiol 108: 497-505

18. Lillioja S, Nyomba BL, Saad MF et al. (1991) Exaggerated early insulin release and insulin resistance in a diabetesprone population: a metabolic comparison of Pima Indians and Caucasians. J Clin Endocrinol Metab 73: 866-876
19. World Health Organization Study Group on Diabetes Mellitus (1985) Technical Report Services No. 727. WHO, Geneva

20. Tataranni PA, Ravussin E (1995) Use of dual X-ray absorptiometry in obese individuals. Am J Clin Nutr 55: 730-734

21. Lillioja S, Bogardus C (1988) Obesity and insulin resistance: lessons learned from the Pima Indians. Diabetes Metab Rev 4: 517-540

22. Banerji MA, Chaiken RL, Gordon D, Kral JG, Lebovitz HE (1995) Does intra- or abdominal adipose tissue in black men determine whether type 2 diabetes mellitus is insulinresistant or insulin-sensitive? Diabetes 44: 141-146

23. Park KS, Rhee BD, Lee KU et al. (1991) Intra-abdominal fat is associated with decreased insulin sensitivity in healthy young men. Metabolism 40: 600-603

24. Macor C, Ruggeri A, Mazzonetto P, Federspil G, Cobelli C, Vettor R (1997) Visceral adipose tissue impairs insulin secretion and insulin sensitivity but not energy expenditure in obesity. Metabolism 46: 123-129

25. Smith CJ, Nelson RG, Hardy SA, Manahan EM, Bennett PH, Knowler WC (1996) Survey of the diet of Pima Indians using quantitative food frequency assessment and 24-hour recall. J Am Diet Assoc 96: 778-784

26. Pratley RE, Thompson DB, Prochazka M (1998) An autosomal genomic scan for loci linked to prediabetic phenotypes in Pima Indians. J Clin Invest 101: 1757-1764

27. Abate N, Garg A, Peshock RM, Stray-Gundersen J, Grundy SM (1995) Relationships of generalized and regional adiposity to insulin sensitivity in men. J Clin Invest 96: 88-98

28. Abate N, Garg A, Peshock RM, Stray-Gundersen J, Adams-Huet B, Grundy SM (1996) Relationship of generalized and regional adiposity to insulin sensitivity in men with NIDDM. Diabetes 45: 1684-1693

29. Goodpaster BH, Leland Thaete F, Simoneau JA, Kelley DE (1997) Subcutaneous abdominal fat and thigh muscle composition predict insulin sensitivity independently of visceral fat. Diabetes 46: 1579-1585 